\title{
Prevalence and determinants of adherence to HAART amongst PLHIV in a tertiary health facility in south-south Nigeria
}

\author{
Afiong O Oku ${ }^{1 *}$, Eme T Owoaje ${ }^{2}$, Olusimbo K Ige ${ }^{2}$ and Angela Oyo-ita ${ }^{1}$
}

\begin{abstract}
Background: Adherence to Highly active antiretroviral therapy (HAART) is a major predictor of the success of HIV/ AIDS treatment. Good adherence to HAART is necessary to achieve the best virologic response, lower the risk of drug resistance and reduce morbidity and mortality. This study therefore aimed to determine the prevalence and determinants of adherence to HAART amongst PLHIV accessing treatment in a tertiary location in Cross River State, Nigeria.
\end{abstract}

Methods: A cross-sectional study was conducted among patients on HAART attending the Presidential Emergency plan for AIDS relief (PEPFAR) clinic of the University of Calabar Teaching Hospital between October-December 2011. A total of 411 PLHIV visiting the study site during the study period were interviewed. PLHIV who met the inclusion criteria were consecutively recruited into the study till the desired sample size was attained. Information was obtained from participants using a semi-structured, pretested, interviewer administered questionnaire. Adherence was measured via patients self report and were termed adherent if they took at least $95 \%$ of prescribed medication in the previous week prior to the study. Data were summarized using proportions, and $x^{2}$ test was used to explore associations between categorical variables. Predictors of adherence to HAART were determined by binary logistic regression. Level of significance was set at $p<0.05$.

Results: The mean age of PLHIV who accessed treatment was $35.7 \pm 9.32$ years. Females constituted $68.6 \%$ of all participants. The self reported adherence rate based on a one week recall prior to the study was $59.9 \%$. The major reasons cited by respondents for skipping doses were operating a busy schedule, simply forgot medications, felt depressed, and travelling out of town. On logistic regression analysis, perceived improved health status [OR 3.11; Cl: 1.58-6.11], reduced pill load [OR 1.25; 95\% Cl: 0.46-2.72] and non-use of herbal remedies [OR 1.83; 95\% Cl: 1.22-2.72] were the major predictors for adherence to HAART. However, payment for ART services significantly decreased the likelihood of adherence to HAART. [OR 0.46; 95\% Cl: 0.25-0.87.].

Conclusions: The adherence rate reported in this study was quite low. Appropriate adherence enhancing intervention strategies targeted at reducing pill load and ensuring an uninterrupted access to free services regimen is strongly recommended.

Keywords: Adherence, PLHIV, HAART, Cross river, Nigeria

\footnotetext{
* Correspondence: afyoku@yahoo.com

${ }^{1}$ Department of Community Medicine, University of Calabar Teaching

Hospital, Calabar, Cross river state, Nigeria

Full list of author information is available at the end of the article
} 


\section{Background}

The Human immunodeficiency virus (HIV) pandemic continues to spread in the population making HIV infection one of the most important public health crises in the world [1]. Globally, about 33.3 million persons were estimated to be infected with HIV/AIDS in 2010, of these, 22.5 million (68\%) are in sub Saharan Africa and about 3 million alone in Nigeria. This makes it the country with the second highest burden of HIV and AIDS in the world after South Africa [1]. The current prevalence rate of HIV in Nigeria as at 2010 based on the sentinel surveillance is $4.1 \%$. Cross River State were the study was conducted currently has the 9th highest prevalence $(7.1 \%)$ in the country as at 2010 and is found in the South-south geopolitical zone of Nigeria [2].

In the absence of a cure, antiretroviral therapy (ART) has remained the only available option that offers the possibility of dramatically reducing HIV/AIDS-related morbidity and mortality, while improving the status of PLHIV. It has proved effective in reducing viral load, improving immune function, [3] and improving the quality of life of PLHIV $[3,4]$. However, successful long-term treatment of HIV requires strict adherence to the Highly Active Antiretroviral Therapy (HAART) regimen $[3,5,6]$. This is especially important in countries such as Nigeria where PLHIV make up $10 \%$ of the global burden of HIV/AIDS [1] and about 1.5 million require treatment [7]. Adherence level of at least $95 \%$ and above has been considered appropriate to achieve therapeutic success, [8-11] as this maintains optimal viral suppression as demonstrated by Paterson and colleagues [11-13]. Failure to observe sustained desired adherence threshold has been associated with dire consequences such as treatment failure, disease progression and emergence of drug resistant HIV/IADS strains $[14,15]$.

With the realization of the central role played by adherence in the success of HIV/AIDS treatment, several studies conducted in various parts of the world including reviews have reported non-adherence rates ranging from $50 \%$ to $80 \%$ in different contexts $[9,10,16]$. However, in reality adherence rates are often lower than 95\% [11] and rates of adherence from previous studies conducted in Nigeria have ranged from as low as $44 \%$ being adherent [17] to more than $95 \%$ from different parts of Nigeria [18]. Most of the previous reports were carried out with fewer PLHIV being on treatment restricted access to ARV drugs unavailability and payment for ARV medications were heavily subsidized.

With wide spread awareness of HIV/AIDS, expansion of treatment and prevention programs that have increased ART access to previously un-served and underserved populations in Nigeria coupled with provision of free ART services, [19] there is a need for implementation of continuous monitoring and evaluation mechanisms for adherence, This is of great importance especially because the key to the success of ART programmes and prevention of treatment failures is hinged on consistently high adherence levels. Scaling up of ARVs alone is definitely not the answer when adherence inconsistencies are not tackled. Therefore, the first step to solving this problem is to assess the determinants of adherence to HAART which may differ across geopolitical zones of the country with their unique characteristics of culture, religion, educational status and health seeking behaviours. The objectives of the present study were to determine the prevalence of adherence to HAART and identify factors associated with adherence.

\section{Methods}

The study was conducted at the President's Emergency plan for AIDS Relief (PEPFAR) clinic now the Specialist treatment clinic of the University of Calabar Teaching Hospital. The Hospital was selected as a centre for the implementation of the President's Emergency plan for AIDS Relief (PEPFAR) by the United States Agency for International Development (USAID) in June 2005. It has since been responsible for the provision of care and support services for PLHIV as well as one of the major centres where PLHIV both in Cross River and other neighbouring states receive anti retroviral therapy. The patient population is about 4,000 , of which more than 2,000 are on treatment. The clinic is run under three units. The paediatric adult and the Prevention of Maternal to Child transmission (PMTCT) clinics.

\section{Study population}

The study population comprised of 411 HIV positive clients who were enrolled and had commenced HAART in UCTH from October 2011- December 2011. They were made of 129 males and 282 females. Participants were consecutively recruited over the study period till the desired sample size was attained. All PLHIV on HAART were eligible to participate except those that satisfied the exclusion criteria. These criteria included PLHIV below 18 years of age, who were attending the clinic but had not commenced HAART, terminally ill patients and pregnant women. The inclusion criteria adopted for the study included consenting out patients diagnosed and confirmed to be HIV positive, at least 18 years of age and had been on HAART for 3 months.

\section{Study design}

A cross-sectional analytical study aimed at documenting the level of adherence among PLHIV on HAART was conducted between October 2011- December 2011.

\section{Data collection instrument}

This consisted of an interviewer administered semi-structured questionnaire which was divided into sections to 
collect relevant information on socio-demographic data, medical profile including treatment experiences at health facility of respondents. Adherence to HAART in the previous seven days of the interview was measured by self-report. The questions were adopted from The Brief Medication Questionnaire self-report tool for screening adherence and barriers to adherence [20]. The degree of adherence from patient self-reporting was estimated using the following formula: [21]

Table 1 The Socio-demographic characteristics of study participants $(n=411)$

\begin{tabular}{|c|c|c|}
\hline Characteristics & Frequency & Percentage \\
\hline \multicolumn{3}{|l|}{ Age group (years) } \\
\hline$<25$ & 31 & 7.5 \\
\hline 25-34 & 171 & 41.6 \\
\hline $35-44$ & 136 & 33.1 \\
\hline $45-54$ & 53 & 12.9 \\
\hline$>55$ & 20 & 4.9 \\
\hline \multicolumn{3}{|l|}{ Sex } \\
\hline Male & 129 & 31.4 \\
\hline Female & 282 & 68.6 \\
\hline \multicolumn{3}{|l|}{ Marital status } \\
\hline Single & 126 & 30.7 \\
\hline Married & 213 & 51.8 \\
\hline Divorced & 36 & 8.8 \\
\hline Widowed & 36 & 8.8 \\
\hline \multicolumn{3}{|l|}{ Educational status } \\
\hline None & 19 & 4.6 \\
\hline Primary & 66 & 16.1 \\
\hline Secondary & 163 & 39.7 \\
\hline Post secondary & 163 & 39.7 \\
\hline \multicolumn{3}{|l|}{ Occupation } \\
\hline Professional/managerial/technical & 126 & 30.7 \\
\hline Skilled manual & 41 & 10.0 \\
\hline Skilled non-manual & 158 & 38.4 \\
\hline Unskilled/unemployed/retired & 86 & 20.9 \\
\hline \multicolumn{3}{|l|}{ Religion } \\
\hline Christianity & 410 & 99.8 \\
\hline Islam & 1 & 0.2 \\
\hline \multicolumn{3}{|l|}{ Place of residence } \\
\hline Within Cross river & 353 & 85.9 \\
\hline Outside Cross river & 58 & 14.1 \\
\hline \multicolumn{3}{|l|}{ Average monthly income } \\
\hline$<N 19,000$ & 277 & 67.4 \\
\hline$\geq N 19,000$ & 134 & 32.6 \\
\hline Median(range) & $7000(0-5,000)$ & \\
\hline
\end{tabular}

\% Adherence over last 7 days

$$
=\frac{\# \text { doses should have taken-\# missed doses } \times 100 \%}{\# \text { Doses should have taken }}
$$

Then, the percentage of adherence to the antiretroviral was estimated by the average of adherence to the drugs. For the purpose of this study a score of $95 \%$ and above represented good adherence and less than 95\% was rated as having poor/suboptimal adherence.

Table 2 Medication/treatment variables including treatment experiences $(n=411)$

\begin{tabular}{|c|c|c|}
\hline Characteristics & Frequency & Percentage \\
\hline \multicolumn{3}{|l|}{ Duration of treatment(months) } \\
\hline$<12$ & 120 & 29.2 \\
\hline $12-24$ & 108 & 26.3 \\
\hline$>24$ & 183 & 44.5 \\
\hline Median duration of treatment(range) & $24(3-192)$ & \\
\hline \multicolumn{3}{|l|}{ Encountered side effects } \\
\hline Yes & 226 & 55.0 \\
\hline No & 185 & 45.0 \\
\hline \multicolumn{3}{|l|}{ Herbal use } \\
\hline Yes & 138 & 33.6 \\
\hline No & 273 & 66.4 \\
\hline \multicolumn{3}{|l|}{ Number of pills/day } \\
\hline$\leq 2$ & 282 & 68.6 \\
\hline $3-4$ & 112 & 27.3 \\
\hline$>4$ & 17 & 4.1 \\
\hline \multicolumn{3}{|l|}{ Presence of opportunistic infection } \\
\hline Yes & 32 & 7.8 \\
\hline No & 379 & 92.2 \\
\hline \multicolumn{3}{|l|}{ Paid for ART services } \\
\hline Yes & 49 & 11.9 \\
\hline No & 362 & 88.1 \\
\hline \multicolumn{3}{|l|}{$\begin{array}{l}\text { Perceived health status as improved } \\
\text { since commencement of HAART }\end{array}$} \\
\hline Improved & 386 & 93.9 \\
\hline No improvement & 25 & 6.1 \\
\hline \multicolumn{3}{|l|}{ Perceived health rating } \\
\hline Excellent & 39 & 9.5 \\
\hline Very good & 253 & 61.6 \\
\hline Good & 92 & 22.4 \\
\hline Fair/poor & 27 & 6.6 \\
\hline \multicolumn{3}{|l|}{ Transportation cost to Health facility } \\
\hline$<N 1000$ & 275 & 66.9 \\
\hline$\geq N 1000$ & 136 & 33.1 \\
\hline
\end{tabular}




\section{Data analysis}

Data were analyzed using SPSS for windows version 19.0. Descriptive and inferential statistical tests were employed. These included bivariate (chi-square) and multivariate (logistic regression) analysis to determine correlates or predictors of adherence. Descriptive statistics (frequencies, proportions, means and standard deviation to summarize variables while Inferential statistics (chi square Test) was used to test the significance of association between categorical variables and level of significance was set at $5 \%$. Logistic regression analysis was used to identify the predictors of adherence to HAART in the study population. Variables entered into the logistic model were those which had earlier been significantly associated on bivariate analysis at $10 \%$ significance derived. Predictors were determined at $5 \%$ significance.

\section{Ethical clearance and consent}

The ethical Committee of the University of Calabar Teaching Hospital reviewed and approved the study procedures and data collection instruments.

\section{Results}

Four hundred and eleven eligible respondents receiving HAART at the PEPFAR clinic UCTH were studied. The mean age of respondents was $35.7 \pm 9.3$ years. The largest proportion of the PLHIV 171 (41.6\%) were in the age group 25-34 years, followed by 136 (33.1\%) in the 35 to 44 age group. The majority of those interviewed were female; $68.6 \%$ and currently married $51.8 \%$. More than a third $39.7 \%$ had attained at least secondary education and
$38.4 \%$ were of the skilled non manual occupational group. Also majority $85.9 \%$ resided within the state and $67.4 \%$ earned less than the minimum wage in Nigeria $(<N 19,000)$ monthly which is equivalent to $\$ 118.75$. Almost all (99.8\%) respondents interviewed were Christians (Table 1). The Medical profile of respondents interviewed (Table 2) revealed that more, 183 (44.5\%) had been on HAART for more than 24 months. The median duration on HAART was 24 months (range 3-192 months). More than half of the study population 226 (55\%) had encountered side effects since the commencement of HAART and majority 273 (66.4\%) were not using any form of herbal treatment alongside their antiretroviral medications. Furthermore, a little over two-thirds of the respondents $282(68.6 \%)$ were on at least 2 pills per day and a vast majority 386 (93.9\%) perceived their health status as improved since their commencement on HAART. A few respondents 49 (11.9\%) of the study population reported paying for services at the treatment site.

Prevalence of adherence to HAART in the study population showed that more than half (59.9\%) of the respondents' attained $95 \%$ adherence to prescribed HAART regimen. The main reasons cited for missing or skipping doses among respondents who missed their medications included being busy (43.8\%), simply forgetting (31.1\%), depression (20\%), frequent travelling (14.8\%) and inconvenient timing for medications schedule $(12.7 \%)$. This is represented in Figure 1.

Factors associated with adherence on bivariate analysis (Tables 3 and 4) were; Being resident outside Cross river state, $42(72.4 \%)$ was significantly more likely to adhere to

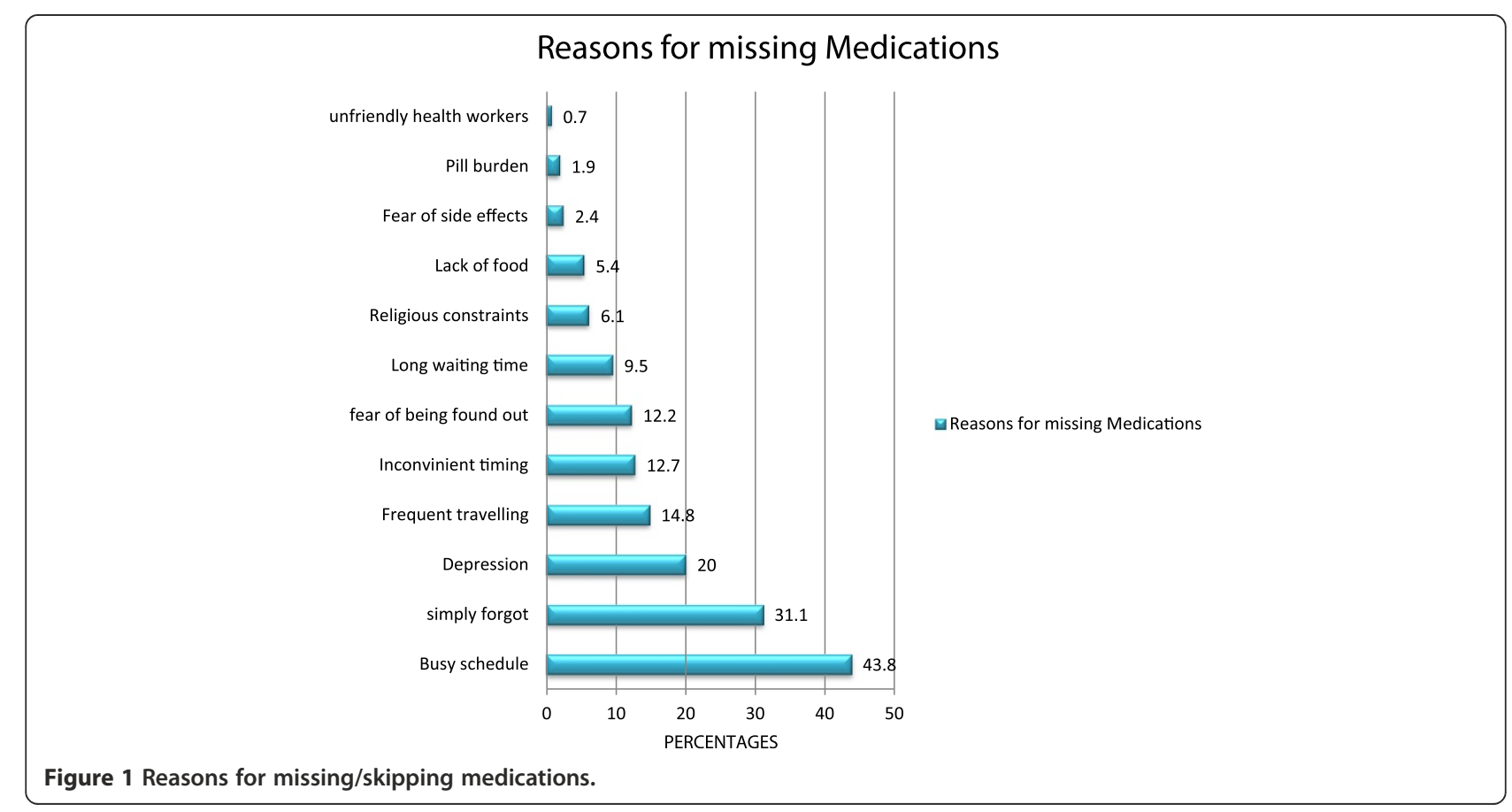


Table 3 Distribution of socio-demographic characteristics, of the study participants by their ART adherence pattern

\begin{tabular}{|c|c|c|c|}
\hline Characteristics & $\begin{array}{l}\text { Good adherence } \\
\qquad \mathrm{N}=\mathbf{2 4 6} \\
\text { Frequency (\%) }\end{array}$ & $\begin{array}{l}\text { Poor adherence } \\
\qquad(\mathrm{N}=165) \\
\text { Frequency }(\%)\end{array}$ & Significance \\
\hline \multicolumn{4}{|l|}{ Age (years) } \\
\hline$\leq 35$ & $137(58.3)$ & $98(41.7)$ & $p=0.46$ \\
\hline$>35$ & 109(61.9) & $67(38.1)$ & $x^{2}=0.55$ \\
\hline \multicolumn{4}{|l|}{ Sex } \\
\hline Male & $78(60.5)$ & $51(39.5)$ & $p=0.864$ \\
\hline Female & 168(59.6) & 114(40.4) & $x^{2}=0.02$ \\
\hline \multicolumn{4}{|l|}{ Marital status } \\
\hline Married & 133(62.4) & $80(37.6)$ & $p=0.27$ \\
\hline Not married & 113(57.1) & $85(42.9)$ & $x^{2}=1.23$ \\
\hline \multicolumn{4}{|l|}{ Level of Education } \\
\hline None & $11(57.9)$ & $8(42.1)$ & \\
\hline Primary & $36(54.5)$ & $30(45.5)$ & $p=0.47$ \\
\hline Secondary & $94(57.7)$ & $69(42.3)$ & $x^{2}=2.54$ \\
\hline Tertiary & 105(64.4) & 58(35.6) & \\
\hline \multicolumn{4}{|l|}{ Residence } \\
\hline Within Cross river & 204(57.8) & 149(42.2) & $p=0.035$ \\
\hline Outside Cross river Herba & $42(72.4)$ & 16(27.6) & $x^{2}=4.43$ \\
\hline \multicolumn{4}{|l|}{ Occupation } \\
\hline Professional managerial/Technical & $80(63.5)$ & $46(36.5)$ & \\
\hline Skilled manual & $23(56.1)$ & 18(43.9) & $p=0.74$ \\
\hline Skilled non manual & $94(59.5)$ & $64(40.5)$ & $x^{2}=1.24$ \\
\hline Unskilled/unemployed/retired & $49(57.0)$ & $37(43.0)$ & \\
\hline \multicolumn{4}{|l|}{ Average monthly income } \\
\hline$\leq \mathrm{N} 19,000$ & 163(58.8) & 114(41.2) & $p=0.55$ \\
\hline$>\mathrm{N} 19,000$ & $83(61.9)$ & $51(38.1)$ & $x^{2}=0.36$ \\
\hline
\end{tabular}

HAART compared with 204 (57.8\%) being resident within the state $(\mathrm{p}<0.05)$. Similarly other significant correlates of adherence included obtaining free ART services, perceived health status as excellent/good and paid more than $N 1000$ on transportation to the health care facility $(\mathrm{p}<0.05)$ (Table 4$)$. The predictors of adherence to HAART amongst PLHIV accessing treatment in PEPFAR clinic UCTH were non use of herbal remedies, obtaining free ART services, perceived improvement in health status, and reduced pill load. Participants not using herbal remedies were more likely to adhere to their prescribed doses compared with those using herbal remedies. Similarly obtaining free ART services, taking not more than two pills per day, and a perceived improvement in health following the commencement of HAART than those who paid for ART services, took more than 2 pills per day, and who reported their perceived health status as not improved. This is presented in Table 5.

\section{Discussion}

The present study aimed to contribute towards addressing gap in knowledge regarding the prevalence and factors associated with treatment adherence among a representative sample of PLHIV accessing treatment site in Cross River State Nigeria.

The self reported adherence reported in the present study was $59.9 \%$. This finding was comparable with other studies done in Nigeria and other African setting, [21-23] but slightly higher than earlier reports by Ilyasu and colleagues in Kano (Northern Nigeria), [18] Nwauche and colleagues (Southern Nigeria) and a study done in Kenya, who reported adherence levels of 54.5\%. 49.2\% and $43.2 \%$ respectively. However adherence level reported in this study was lower than seen in other studies [22,24-26]. Our current findings showed that about two fifths of patients interviewed were non adherent both in terms of dose adherence and timing. Emphasis should therefore be placed on adherence to HAART 
Table 4 Distribution of Medical profile/treatment experiences of the study participants by their ART adherence pattern

\begin{tabular}{|c|c|c|c|}
\hline Characteristics & $\begin{array}{c}\text { Good adherence } \\
\mathrm{N}=246 \text { Frequency }(\%)\end{array}$ & $\begin{array}{c}\text { Poor adherence } \\
(\mathrm{N}=165) \text { Frequency }(\%)\end{array}$ & Significance \\
\hline \multicolumn{4}{|c|}{ Use of Herbal remedies } \\
\hline Yes & $74(53.6)$ & $64(46.4)$ & $p=0.07$ \\
\hline No & $172(63.0)$ & $101(37.0)$ & $x^{2}=3.36$ \\
\hline \multicolumn{4}{|c|}{ Number of pills/day } \\
\hline$\leq 2$ & $161(57.1)$ & $121(42.9)$ & $p=0.091$ \\
\hline$>2$ & $85(65.9)$ & $44(34.1)$ & $x^{2}=2.85$ \\
\hline \multicolumn{4}{|c|}{ Opportunistic infections } \\
\hline Yes & $18(56.2)$ & 14(43.8) & $p=0.665$ \\
\hline No & $228(60.2)$ & 151(39.8) & $x^{2}=1.88$ \\
\hline \multicolumn{4}{|c|}{ Paid for ART services } \\
\hline Yes & $21(42.9)$ & $28(57.1)$ & $p=0.01$ \\
\hline No & $225(62.5)$ & 137(37.8) & $x^{2}=6.69$ \\
\hline \multicolumn{4}{|c|}{ Rating of Perceived Health } \\
\hline Excellent/good & $238(62.0)$ & 152(39.4) & $p=0.01$ \\
\hline Fair/poor & $8(29.6)$ & $19(70.4)$ & $x^{2}=10.1$ \\
\hline \multicolumn{4}{|c|}{ Perceived health status } \\
\hline Improving & 234(60.6) & 152(39.4) & $p=0.21$ \\
\hline Not improving & $12(48.0)$ & 13(52.0) & $x^{2}=1.56$ \\
\hline \multicolumn{4}{|c|}{ Encountered side effects } \\
\hline Yes & $126(55.8)$ & $100(44.2)$ & $p=0.061$ \\
\hline No & 120(64.9) & $65(35.1)$ & $x^{2}=3.52$ \\
\hline \multicolumn{4}{|c|}{ Cost of transportation to health centre } \\
\hline$<N 1000(\$ 6.25)$ & $154(56.0)$ & $121(44.0)$ & $p=0.023$ \\
\hline$>N 1000(\$ 6.25)$ & $92(67.6)$ & $44(32.4)$ & $x^{2}=5.14$ \\
\hline \multicolumn{4}{|c|}{ Duration on HAART(months) } \\
\hline$<24$ & $116(60.1)$ & 77(39.9) & $p=0.864$ \\
\hline$\geq 24$ & 130(59.6) & $88(40.4)$ & $x^{2}=0.029$ \\
\hline
\end{tabular}

especially during counselling sessions as this is required for optimal clinical response and complete viral suppression.

The major reasons cited by participants for missing doses included; operating a busy schedule and simply forgetting medications. These two reasons though related to one another have been cited by several studies as the main risk factors for suboptimal adherence [21,23,27-29]. Another important reason given by respondents for skipping or missing medications which is note worthy was feeling depressed. Approximately a fifth of the study population indicated feeling depressed as a reason for poor adherence to medications. This was similar to findings conducted in USA in 2010 where patients with symptoms of depression had higher rates of suboptimal adherence [30]. Issues bothering around stigma and discrimination, personality traits, fear of being discovered, lack of social support, and poorer health outcomes may contribute strongly to emotional non-adjustment to HIV/AIDS, depression and loss of interest in ones treatment. This would ultimately result in poor adherence to medications amongst PLHIV.

Most socio-demographic characteristics such as age, sex, marital status, educational attainment did not significantly affect adherence levels amongst our study population. This corroborates the findings of some authors [17,28,31,32] but refutes the findings of others were certain sociodemographic variables were associated with being adherent to HAART $[24,33]$.

Medication adherence was found to be significantly associated with non use of Traditional herbal medicines. The effect of the use of herbal remedies in addition to HAART was noted in this study. Non herbal use was demonstrated as a significant predictor of adherence in 


\begin{tabular}{|c|c|c|c|}
\hline Independent Variable & $\begin{array}{l}\text { Odds } \\
\text { ratio }\end{array}$ & $\begin{array}{l}95 \% \text { confidence } \\
\text { interval }\end{array}$ & p-value \\
\hline \multicolumn{4}{|l|}{ Use of herbal remedies } \\
\hline No & 1.83 & $1.22-2.72$ & 0.003 \\
\hline Yes & 1 & & \\
\hline \multicolumn{4}{|l|}{ Paid for ART services } \\
\hline Yes & 0.46 & $0.25-0.87$ & 0.017 \\
\hline No & 1 & & \\
\hline \multicolumn{4}{|l|}{ Pill number } \\
\hline$\leq 2$ pills/day & 1.84 & $1.25-2.72$ & 0.002 \\
\hline$>2$ pills/day & 1 & & \\
\hline \multicolumn{4}{|c|}{$\begin{array}{l}\text { Description of perceived } \\
\text { health status }\end{array}$} \\
\hline Improving & 3.11 & $1.58-6.11$ & 0.001 \\
\hline Not improving & 1 & & \\
\hline \multicolumn{4}{|l|}{ Residence } \\
\hline Outside Cross river & 0.76 & $0.40-1.47$ & 0.42 \\
\hline Within Cross river & 1 & & \\
\hline \multicolumn{4}{|l|}{ Encountered side effects } \\
\hline Yes & 0.92 & $0.65-1.29$ & 0.61 \\
\hline No & 1 & & \\
\hline \multicolumn{4}{|l|}{ Transportation costs } \\
\hline$<N 1000(\$ 6.25)$ & 0.76 & $0.50-1.16$ & 0.20 \\
\hline$\geq N 1000(\$ 6.25)$ & 1 & & \\
\hline
\end{tabular}

this study. This finding is in agreement with a study conducted in Ilorin, (south western Nigeria) were the use of herbal medicines was a major risk factor for non adherence [34] and a study done in South Africa by Peltzer et al. which demonstrated non use of herbal remedies as a major facilitator of adherence [26]. The reason respondents may consider using herbal remedies could be attributable to the fact that some patients may gradually be losing faith in their anti-retrovirals which most are aware does not provide a cure and are opting for herbal remedies. Secondly, the proliferation of alternative healers and a claim on the media by traditional medicine practitioners of an instant cure for HIV infection may cause some to abandon their treatment.

Pill burden also significantly affected adherence in the present study. Respondents on more than two pills per day were less likely to adhere to their treatment compared to those on at least two pills per day. This finding was also identified as a significant predictor of adherence in a study done by Falang and colleagues in Jos [25] and Sow et al. in Senegal [35] where pill burden was reported to have a strong impact on adherence. Similarly, in India Cauldbeck et al. demonstrated that patients who attained $100 \%$ adherence took fewer pills [36]. This could be attributable to the fact that these patients probably because of their busy schedules may have been unable to incorporate their drugs schedule into their daily schedule or may be developing pill fatigue. Reducing pill load as well as dosing schedules to once or twice daily has been found to be associated with better adherence [25].

Self reported improved health status was significantly associated with adherence amongst our study population. The odds of adherence among those who rated their health status as improved was three times compared to those who perceived their health as not improved. This study was in agreement with another study [37] where staying healthy was a key motivator of adherence to treatment. In contrast to our findings, Olowookere and colleagues in south western Nigeria reported that feeling good/healthy, were risk factors for non-adherence. They further reported that most patients tend to abandon treatment once there was an improvement in their health [21,23].

Obtaining free treatment at ART clinics was a significant predictor of adherence to treatment. Respondents who didn't pay for obtaining ART services were two times better adherers compared to those who paid for services. This was in keeping with studies done in the south western part of Nigeria, [33] and another study done in Botswana when cost were removed as a barrier, adherence was predicted to increase from 54\% to $74 \%$ [11]. Financial constraints among respondents were a major deterrent to adherence as observed in this study. Although drugs were given free of charge in most health facilities offering ART services, patients are still required to pay some user fees at health facility e.g. opening of folders, certain laboratory investigations and treatment of opportunistic infections. In addition there are some indirect costs these patients bear e.g. cost of transportation to the health care facility. Non-payment of services at every HAART clinics should be enforced and providing free treatment for opportunistic infections will also go a long way in improving adherence.

Certain limitations of this study should be recognized. The cross-sectional nature of the survey did not allow for inferences to be drawn as to causal relationship among variables. The use of self report medication adherence to assess medication adherence was a limitation in this study since participants had to recall their medication adherence in the previous week. Concerted efforts were made to reduce recall bias by limiting recall of medication to 7 days prior to the study which was in itself a limitation because of the possibility that subjects would either over- or underestimated their adherence to HAART. This was further worsened by the inability to corroborate patient self- report of adherence with viral loads and CD4 responses because of financial and logistic constraints of frequent laboratory monitoring. This was because restricted access to patient's folders. 


\section{Conclusion}

This study showed that medication adherence rate was low among PLHIV accessing treatment in UCTH Calabar, Nigeria. It is also obvious that there are barriers to adherence therefore efforts should be targeted and assessed for each patient so that appropriate adherence enhancing interventions can be undertaken. The authors therefore recommend that non-payment of services at every ART clinics and provision of free treatment should also include opportunistic infections and required investigations. This will go a long way in improving adherence. Also the focus during counselling sessions should discourage the use of traditional herbal remedies alongside HAART which has been seen to affect adherence in the present study. In addition, curtailing the activities of Alternative medical practitioners in the country claiming to have found a cure for HIV/AIDS would be of immense help. Pharmaceutical companies involved in manufacture of ARVs should ensure that all recommended ARV regimens should consist of not more than two pills per day.

\section{Abbreviations}

AIDS: Acquired immune deficiency syndrome; ART: Antiretroviral therapy; HAART: Highly active antiretroviral drugs; HIV: Human Immunodeficiency virus; PEPFAR: President's Emergency plan for AIDS Relief; PMTCT: Prevention of Maternal to Child transmission; PLHIV: People living with HIV/AIDS; UCTH: University of Calabar Teaching Hospital; USAID: United States Agency for International Development.

\section{Competing interests}

The authors declare that they have no competing interests.

\section{Authors' contributions}

OA conceived, designed and coordinated the study, she carried out statistical analysis and drafted the manuscript; OE contributed by means of her competence and experience in reviewing the manuscript critically for its intellectual content and also participated in the conception and design of the study. $1 \mathrm{O}$ and $\mathrm{OA}$ participated in the design of the study, questionnaire and critically reviewed the manuscript. All authors read and approved the final manuscript.

\section{Acknowledgements}

The authors would like to thank the staff of the President's Emergency plan for Aids Relief (PEPFAR) clinic in the department of Family Medicine,

University of Calabar Teaching Hospital for the support and assistance during the collection of data.

\section{Author details}

${ }^{1}$ Department of Community Medicine, University of Calabar Teaching Hospital, Calabar, Cross river state, Nigeria. ${ }^{2}$ Department of Community Medicine, University College Hospital, Ibadan, Nigeria.

Received: 1 March 2013 Accepted: 21 August 2013

Published: 30 August 2013

\section{References}

1. UNAIDS: 2008 Report on the global. HIV/AIDS epidemic 2008. Geneva Switzerland; 2008.

2. Federal Ministry of Health(FMOH): 2010 National HIV sero- prevalence Senntinnel Survey. Abuja: Federal Ministry of Health; 2010.

3. Rao D, Kekwaletswe TC, Hosek S, Martinez J, Rodriguez F: Stigma and social barriers to medication adherence with urban youth living with HIV. AIDS Care 2007, 19(1):28-33.
4. Lewis MP, Colbert A, Erlen J, Meyers M: A Qualitative study of persons who are $100 \%$ adherent to antiretroviral therapy. AIDS Care 2006, 18(2):140-148

5. Moatti JP, Spire B: Economic and socio-behavioral issues related to highly active antiretroviral therapies for HIV infection: the contribution of social science research. Med Sci 2003, 19(8):878-884.

6. Tapper M, Flexner C, Eron JJ, Molina J: Simplifying antiretroviral therapy. AIDS Care 2004, 14(7):355-367.

7. National Agency for the control of AIDS (NACA): Antiretroviral therapy(ART) in Nigeria. Fact sheet 2011. ; 2011.

8. McPherson-Baker S, Jones D, Duran R, Klimas N, Schneiderman N: Development and implementation of a medication adherence training instrument for persons living with HIV (The MATI). Behav Modif 2005, 29(2):286-317.

9. Amico KR, Toro-Alfonso J, Fisher JD: An empirical test of the Information, Motivation and Behavioural Skills model of antiretroviral therapy adherence. AIDS Care 2005, 17(6):661-673.

10. Remien RH, Bastos FI, Terto Jnr V, Raxach JC, Pinto RM, Parker RG, et al: Adherence to antiretroviral therapy in a context of universal access, in Rio de Janeiro, Brazil. AIDS Care 2007, 19(6):740-748.

11. Weiser S, Wolfe W, Bangsberg D: Barriers to Antiretroviral Adherence to patients living with HIV infection and AIDS in Botswana. J Acquir Immune Defic Syndr 2003, 34(3):281-288.

12. Weiss $L$, French $T$, Finkelstein $R$, Waters $M$, Mukherjee RBA: HIV-related knowledge and adherence to HAART. AIDS Care 2003, 15(5):673-679.

13. Paterson G, Swindells S, Mohr J: Adherence to protease inhibitor therapy and outcome in patients with HIV infection. Ann Intern Med 2000, 133:21-30.

14. Nilsson-Schönnesson L, Diamond PM, Ross MW, Williams M, Bratt G: Baseline predictors of three types of antiretroviral therapy (ART) adherence A 2-year follow-up. AIDS Care 2006, 18(3):246-253.

15. Poppa A, Davidson D, Deutsch J, Dan G, Fisher M, Head S: British HIV Association (BHIVA)/British Association for sexual health and HIV (N'BASHH) guidelines on provision of adherence support to individuals receiving antiretroviral therapy. HIV Med 2004, 5(S):46-60.

16. Reynolds NR, Testa M, Marc L, Chesney M, Neidig J, Smith S, et al: Factors influencing medication adherence beliefs and self-efficacy in persons naïve to antiretroviral therapy: A multicentre, cross-sectional study. AIDS Behaviour 2004, 8(2):141-150.

17. Mohammed MD: R. S. Adherence to antiretroviral drugs in North-Central zone of Nigeria. East Cent Afr J Pharm Sci 2004, 7(3):52-55.

18. Iliyasu I, Kabir M, Abubakar I, Babashani M, Zubair Z: Compliance to antiretroviral therapy among AIDS patients in Amino Kano Teaching Hospital, Kano. Niger J Med 2005, 14(3):290-294.

19. Monjok E, Smesny A, Okokon IB, Mgbere O, Essien J: Adherence to antiretroviral therapy in Nigeria: An overview of research studies and implications for policy and practice. HIV/AIDS - Res Palliat Care 2010, 2:69-76.

20. Svarstad B, Chewning B, Sleath B, Claessonc C: The brief medication questionnaire: $A$ tool for screening patient adherence and barriers to adherence. Patient Educ Couns 1998, 37:113-124.

21. Olowookere SA, Fatiregun AA, Akinyemi JO, Bamgboye AEGKO: Prevalence and determinants of nonadherence to highly active antiretroviral therapy among people living with HIV/AIDS in Ibadan, Nigeria. J Infect Dev Ctries 2008, 2(5):369-372.

22. Shaahu V, Lawoyin T, Sangowawa A: Adherence to Highly Active antiretroviral therapy(HAART) at a Federal Medical Center. Afr J Med Sci 2008, 37:29-36

23. Agu KA, Okojie O, Oqua D, King RC, Omonaiye O, Onuoha C, et al: Medication Adherence and Risk factors for Non-adherence among Patients taking Highly Active Antiretroviral Therapy. West Afr J Pharm 2011, 22(1):19-26.

24. Uzochukwu B, Onwujekwe O, Onoka A, Okoli C, Uguru N, Chukwuogo O: Determinants of non-adherence to subsidized anti-retroviral treatment in southeast Nigeria. Health Policy Plan 2009, 24:189-196.

25. Falang KD, Akubaka N, Jimam NS: Patient Factors impacting Antiretroviral drug adherence in a Nigerian tertiary Hospital. J Pharmacol Pharmacother 2012, 3(2):138-142.

26. Peltzer K: Preez NF-d, Ramlagan S, Anderson J: Antiretroviral treatment adherence among HIV patients in KwaZulu-Natal. South Afr BMC Public Health 2010, 10:1-10 
27. Amberbir A, Woldemichael K, Getachew S, Girma B, Deribe K: Predictors of adherence to antiretroviral therapy among HIV-infected persons: a prospective study in Southwest Ethiopia. BMC Publ Health 2008, 8(265):1-10.

28. Talaam NC, Gatongi P, Rotich S: Factors Affecting Antiretroviral Drug Adherence among HIV/AIDS Adult Patients attending HIV/AIDS clinic at Moi Teaching and Refferal Hospital, Eldoret, Kenya. East Afr J Public Health 2008, 5(2):74-78

29. Wakibi SN, Ng'ang'a ZW, Mbugua GG: Factors associated with non-adherence to highly active antiretroviral therapy in Nairobi, Kenya. AIDS Res Ther 2011, 43:1-8.

30. Kacanek D, Jacobson D, Spiegelman D, Wancke C, Isac R, Wilson I: Incident depression symptoms are associated with poorer HAART adherence: A longitudinal analysis from the nutrition for Healthy living study (NFHL). J Acquir Immune Defic Syndr 2010, 53(2):266-272.

31. Kleeberger C, Phair J, Strathdee S, Detels R, Kingsley L, Jacobson L: Determinants of heterogenous adherence to HIV antiretroviral therapies in the Multicentre AIDS Cohort Study. J Acquir Immune Defic Syndr 2001, 26(1):82-92.

32. Gifford A, Bormann J, Shively M, Wright B, Richman D, Bozzette S: Predictors of self-reported adherence and plasma HIV concentrations in patients on multidrug antiretroviral regimens. J Acquir Immune Defic Syndr 2000, 23:386-395.

33. Afolabi MO, ljadunola KT, Fatusi AO, OA O: Determinants of adherence to antiretroviral drugs among people living with HIV/AIDS in the lfe-ljesa of Osun State, Nigeria. Afr J Prim Health Care Fam Med 2009, 1(1):6.

34. Bello SI: HIV Patients adherence to ART in Sobi Specialist Hospital, Illorin Nigeria Glob J Med Res 2011, 11(2):16-21.

35. Sow PG, Toure K, Coume M, Dia AT, Traore I: Predictors of ART adherence among HIV infected individuals in Dakar, Senegal. J Med Med Sci 2012, 3(4):212-216.

36. Cauldbeck MB, O'Connor C, O'Connor MB, Saunders JA, Rao B, Mallesh VG, et al: Adherence to anti-retroviral therapy among HIV patients in Bangalore. India AIDS Res Ther 2009, 6(7):1-8.

37. Malcolm S, Ng J, Rosen R, Stone V: An examination of HIV/AIDS patients who have excellent adherence to HAART. AIDS Care 2003, 15(2):251-61.

doi:10.1186/1471-2334-13-401

Cite this article as: Oku et al:: Prevalence and determinants of adherence to HAART amongst PLHIV in a tertiary health facility in south-south Nigeria. BMC Infectious Diseases 2013 13:401.

\section{Submit your next manuscript to BioMed Central and take full advantage of:}

- Convenient online submission

- Thorough peer review

- No space constraints or color figure charges

- Immediate publication on acceptance

- Inclusion in PubMed, CAS, Scopus and Google Scholar

- Research which is freely available for redistribution 